Article

\title{
Estimating Vegetation Water Content and Soil Surface Roughness Using Physical Models of L-Band Radar Scattering for Soil Moisture Retrieval
}

\author{
Seung-Bum Kim ${ }^{1}$, , Huanting Huang ${ }^{2}$, Tien-Hao Liao ${ }^{1}$ and Andreas Colliander ${ }^{1}$ \\ 1 Jet Propulsion Laboratory, California Institute of Technology, Pasadena, CA 91109, USA; \\ thaoliao@outlook.com (T.-H.L.); Andreas.Colliander@jpl.nasa.gov (A.C.) \\ 2 University of Michigan, Ann Arbor, MI 48109, USA; huanght@umich.edu \\ * Correspondence: seungbum.kim@jpl.nasa.gov
}

Received: 20 November 2017; Accepted: 2 April 2018; Published: 4 April 2018

\begin{abstract}
Soil surface roughness and above-ground vegetation water content (VWC) are estimated by inverting physical models for L-band scattering and absorption at $40^{\circ}$ incidence angle using ground, airborne and Soil Moisture Active Passive (SMAP) radar data. The spatial resolution varies from field scale (airborne and ground) to $3 \mathrm{~km}$ (SMAP). The temporal resolution is defined by the length and interval of observation time windows (weeks to three months for surface roughness, and three to seven days for VWC). The validation of the roughness estimates shows an accuracy of $25 \%$ (bare surface) and 29 to $46 \%$ (croplands and pasture). The correlation degrades as vegetation becomes thicker, indicating the stronger scattering and absorption by thicker vegetation. The roughness retrievals with the SMAP data are within the physical range of $0.5 \mathrm{~cm}$ to $4 \mathrm{~cm}$. They show larger values in croplands than in natural terrain. The VWC estimate modifies a 'first guess' (in situ values for the airborne experiment; and 16-daily climatology for SMAP). The VWC retrievals correctly follow the full growth of crops and the RMSE is smaller than $20 \%$ in the airborne retrievals: the correlation ranges from 0.57 to 0.91 . These results demonstrate that the forward model inversion has a potential to retrieve VWC for the four major crops over the entire phase of the crop growth. The VWC retrievals from the SMAP data revised the climatology first guess more in the croplands, where the climatology is more likely to depart from the contemporaneous condition than in natural landcover. The value of this work lies in the fact that the surface roughness at the footprint scale is difficult to characterize and a global VWC product at SMAP's spatial scale from microwave observations is rare, and that this paper presents a plausible pathway towards such products. The estimates at these temporal and spatial scales derived from microwave observations will be useful for studies of climate, agriculture, and soil moisture.
\end{abstract}

Keywords: surface roughness; vegetation water content; soil moisture; synthetic aperture radar

\section{Introduction}

Accurate knowledge of water content within the above ground vegetation (VWC) is important in characterizing plant productivity and crop growth, which are controlled by the water availability within a root zone [1]. VWC also controls evapotranspiration: it returns two thirds of precipitation over land to the atmosphere [2], $60 \%$ of which is through vegetation [3]. With regard to surface roughness, the interest of this paper lies in the microwave scale roughness on the order of the wavelengths (e.g., 21 to $24 \mathrm{~cm}$ in free space at L-band). At these scales, scattering occurs by Bragg resonance and physical/geometric optics processes. In comparison, the scattering is due to the changes of incidence angle in the case of larger-scale terrain slope. The microwave scale roughness is found useful for monitoring agricultural tillage practices $[4,5]$ in compliance with a farm subsidy and soil conservation. 
Another benefit of accurate knowledge of surface roughness and VWC originates from its critical role in achieving reliable estimates of surface soil moisture. They parameterize the effects of scattering and absorption of microwave signals. They are two of the main parameters in the zeroth-order single-scattering tau-omega model [6], single-scattering water cloud model [7] or Bayesian model [8] for microwave emission and scattering. A merit of using $\sigma^{0}$ for roughness estimate to help radiometer-based soil moisture retrieval originates from the strong sensitivity of $\sigma^{0}$ on roughness as explored by Theis et al. [9].

Coarse-resolution estimates of VWC and surface roughness have been made using the tau-omega model. For example, VWC is estimated using the data from L-band Soil Moisture Active Passive [10], L-band Soil Moisture Ocean Salinity (SMOS) [11-13], and X-band/higher Advanced Microwave Scanning Radiometer [14]. Surface roughness was retrieved using SMOS data [15]. As common with these retrievals, the spatial resolution is defined by the raw radiometer footprint ( $25 \mathrm{~km}$ to $36 \mathrm{~km})$. In comparison, synthetic aperture radar (SAR) offers a better resolution ( $3 \mathrm{~km}$ with SMAP and tens of meters for scan SAR). Noting that these two parameters are influential in characterizing SAR backscattering coefficients $\left(\sigma^{0}\right)$, they may be retrieved using $\sigma^{0}$ data at the spatial resolution SAR.

High-resolution VWC was derived using shortwave infrared data at 30 to $250 \mathrm{~m}$ resolution [16] rather than using SAR data. However, leaves are opaque at infrared frequency. As a result, the retrieval becomes saturated when the canopy fully covers the ground. Then, VWC of trunks under the canopy may not be well represented. To mitigate, an empirical adjustment (stem factor) was introduced [16]. In comparison, C- or L-band SAR signal penetrates thin leaves, which offers the feasibility of estimating high-resolution VWC. A linear relationship was found for some crops between VWC and radar polarimetric signature $[17,18]$, but the applicability to more diverse types of crops has yet to be confirmed. The effect of vegetation on $\sigma^{0}$ was corrected implicitly $[19,20]$, without explicit retrieval of VWC. In this paper, we explicitly derive VWC.

High-resolution surface roughness values for bare surfaces [21-23] were estimated by inverting radar scattering models. However, solutions for vegetated surfaces are rare, where vegetation effects on $\sigma^{0}$ reduce signal-to-noise ratio for roughness retrieval. An empirical relationship was studied between roughness and $\sigma^{0}$ over harvested fields [4]: more comprehensive methods are desired to attain wider applicability. Azzari et al. [5] used temporal stacks of Sentinel-1 SAR data to estimate the effect of surface roughness and detect tillage practices in the US corn belt. Since the temporal changes in $\sigma^{0}$ respond to other causes as well, such as variations in vegetation and soil moisture, rigorous estimation or correction of all the major parameters contributing to $\sigma^{0}$ is important, which is the approach adopted in this paper.

Our goal is to explore the feasibility of retrieving high-resolution VWC and surface roughness using L-band radar $\sigma^{0}$. The capabilities to retrieve such information will be highly valuable (1) to fill the void of the high-resolution information and (2) because we exploit the L-band's capability. L-band signals with wavelengths longer than canopy structures penetrate the vegetation layer down to the soil, as evidenced by strong scattering from soil surface for grass, soybean, and wheat vegetation and by strong double-bounce scattering for savanna (Figure 7 of [24]). The reflections from the soil surface may allow the retrieval of surface roughness. Among other factors, the degree of penetration and the magnitude of $\sigma^{0}$ depend on VWC, which permits the retrieval of VWC using $\sigma^{0}$ observations.

To implement the retrieval, we developed physical models for L-band scattering and absorption from the vegetated surfaces using discrete scattering processes $[25,26]$. The models were designed to perform soil moisture retrieval. Since rigorous correction of the effects by vegetation and surface roughness is required, the parameters are derived and used for the correction. When evaluated using in situ data, the simulated $\sigma^{0}$ was accurate to 1 to $2 \mathrm{~dB}$ root mean square error (RMSE), and the soil moisture retrieval error ranges from, 0.042 to $0.075 \mathrm{~m}^{3} / \mathrm{m}^{3}$ (as a reference of 'good' retrieval, the accuracy targets of SMAP radiometer and radar soil moisture products are 0.04 to $\left.0.06 \mathrm{~m}^{3} / \mathrm{m}^{3}\right)[22,24,25,27-29]$. The encouraging evaluation of $\sigma^{0}$ and soil moisture leads us to explore the feasibility of the retrieval of VWC and surface roughness. 
This paper is organized as follows. Section 2 describes the retrieval method. Section 3 presents the data used to evaluate the approach. The assessment and discussions of the retrieval performance are provided in Section 4.

\section{Method}

Physical forward models for radar scattering from vegetated surface are used for retrieval of VWC and surface roughness. The scattering theory of distorted Born approximation (DBA, [30]) may apply to a single scattering process involving soil permittivity, VWC, roughness, and $\sigma^{0}$ :

$$
\sigma_{p q}^{t}=\sigma_{p q}^{s}(\varepsilon, s, l) \exp \left(-2 \tau_{p q}(V W C)\right)+\sigma_{p q}^{v}(V W C)+\sigma_{p q}^{s v}(V W C, \varepsilon, s, l) .
$$

In this expression, $\sigma_{p q}^{t}$ represents the total radar scattering cross-section in polarization $p q$ $(\mathrm{HH}, \mathrm{VV}$, or $\mathrm{HV}), \sigma_{p q}^{s} \exp \left(-2 \tau_{p q}\right)$ denotes the scattering cross-section of the soil surface modified by the two-way vegetation attenuation, $\sigma_{p q}^{v}$ is the scattering cross-section of the vegetation volume, and $\sigma_{p q}^{s v}$ represents the scattering interaction between the soil and vegetation. The quantity $\varepsilon$ is the complex dielectric constant of bare soil, $s$ and $l$ are the rms height and the correlation length for bare surface roughness, respectively, and $\tau$ as a function of VWC is the vegetation opacity along the slant path of a radar beam. Any of $\varepsilon, s, l$, and VWC may be prescribed as an input or be estimated through inversion.

The implementation of Equation (1) incorporates a full-wave numerical calculation of bare surface scattering [31]. For light vegetated surfaces, the scattering theory of the DBA is applied to model the single-scattering radar backscattering from discrete scatterers for a vegetation-covered soil layer, composed of three elements (surface, volume, and double-bounce). For thick vegetation such as corn, a radiative transfer theory allows the modeling of multiple scattering [29]. When scatters are close enough to produce coherent scattering such as soybean, the coherent modeling significantly improved the accuracy [27]. Full details of the forward model development are available in Kim et al. [25]. These models were trained to agree with airborne or ground observations with residual co-pol RMSE of $\sim 1.5 \mathrm{~dB}$ (bare soil [31]), $1.8 \mathrm{~dB}$ (grass [25]), 1 dB (soybean [27]), 1.7 dB (corn [29]), and $2.7 \mathrm{~dB}$ (woody savanna [32]).

The retrieval algorithm was developed to estimate soil moisture using SMAP's radar observations. It inverts the lookup table representation of the forward model per each vegetation type (Equation (1)). The full details are available in Kim et al. [25], together with the successful evaluation of the soil moisture estimates reported in the publications by the authors.The time-series of dual-copol observations are used as inputs. The lookup table (Figure 1) is searched to find a soil moisture solution by minimizing the cost function $C$ between modeled and observed $\sigma^{0}$ :

$$
\begin{aligned}
& C\left(\bar{s}, \bar{\varepsilon}_{r 1}, \bar{\varepsilon}_{r 2}, \ldots, \bar{\varepsilon}_{r N}\right)= \\
& w_{1, H H}\left(\sigma_{H H, 1}^{0}-\sigma_{H H, f w d}^{0}\left(\bar{s}, \bar{\varepsilon}_{r 1}, \bar{f}_{1} V W C_{1}\right)+\bar{c}\right)^{2}+w_{1, V V}\left(\sigma_{V V, 1}^{0}-\sigma_{V V, f w d}^{0}\left(\bar{s}, \bar{\varepsilon}_{r 1}, \bar{f}_{1} V W C_{1}\right)+\bar{c}\right)^{2}+ \\
& w_{2, H H}\left(\sigma_{H H, 2}^{0}-\sigma_{H H, f w d}^{0}\left(\bar{s}, \bar{\varepsilon}_{r 2}, \bar{f}_{2} V W C_{2}\right)+\bar{c}\right)^{2}+w_{2, V V}\left(\sigma_{V V, 2}^{0}-\sigma_{V V, f w d}^{0}\left(\bar{s}, \bar{\varepsilon}_{r 2}, \bar{f}_{2} V W C_{2}\right)+\bar{c}\right)^{2}+\ldots+ \\
& w_{N, H H}\left(\sigma_{H H, N}^{0}-\sigma_{H H, f w d}^{0}\left(\bar{s}, \bar{\varepsilon}_{r N}, \bar{f}_{N} V W C_{N}\right)+\bar{c}\right)^{2}+w_{N, V V}\left(\sigma_{V V, N}^{0}-\sigma_{V V, f w d}^{0}\left(\bar{s}, \bar{\varepsilon}_{r N}, \overline{f_{N}} V W C_{N}\right)+\bar{c}\right)^{2},
\end{aligned}
$$

where the overbar denotes parameters that are retrieved. Numeric subscripts, $1,2, N$, are time indexes. Radar backscattering coefficients from observations and from the forward model are shown by $\sigma^{0}$ and $\sigma_{\mathrm{fwd}}^{0}$ (both in $\mathrm{dB}$ ), respectively. $s$ is the bare surface roughness, $\varepsilon$ is the soil dielectric constant, $w$ is the weight (uniform between channels and time-instances because the error characteristics of $\sigma^{0}$ are uniform across the channels, see Appendix of [22]). $f_{i}$ is a retrieved factor for VWC adjustment, ranging from 0 and 2. $c$ denotes the correction of any bias between measurement and model (physical sources of the bias in the forward model include missing physics such as the effect of topography, and mismatch of the number of discrete scatterers between nature and model). 


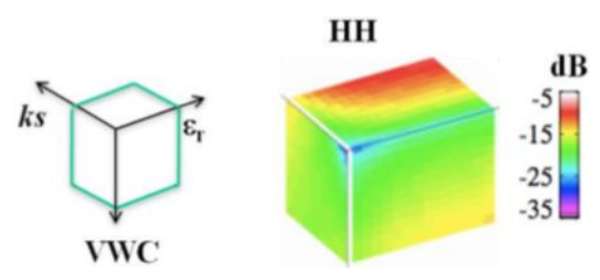

Figure 1. Example of a three-dimensional lookup table (called datacube) of the forward scattering model to use during the inversion [25].

The details of VWC and roughness retrieval approaches are:

- Soil surface roughness is retrieved simultaneously as soil moisture and VWC are estimated. Surface roughness is specified as constant in time, which is the key concept of the time-series retrieval method to avoid ill-conditions. In comparison, VWC and soil moisture estimates are allowed to vary temporally.

- VWC estimate modifies a 'first guess'. The first guess is the in situ values for airborne campaign data and 16-daily MODIS-climatology for SMAP. The modification factor $f_{i}$ can be either static or dynamic in time. When the VWC is not expected to change in time over natural terrain, a static $f$ formulates Equation (2).

- On the other hand, over croplands where the vegetation changes significantly with the crop growth, $f_{i}$ is allowed to vary dynamically. To prevent ill-conditions, regularization or limits are required. By acknowledging that plant growth is steady, VWC change is allowed to vary up to a fixed limit (1.25 times of the VWC retrieval at the previous time step during the soybean growth [27]), and up to pre-defined values for the other respective crops.

An ill-posed condition would develop if the number of unknowns is larger than the number of independent observations. To prevent the condition, the concept of time-series retrieval was introduced [22]. According to this concept, the number of unknowns is $N+3$, where $N$ is the number of time-series instances and three corresponds to time-invariant surface roughness, static vegetation scaling factor, and bias. During the time period of $N$ SMAP measurements, there are $2 N$ co-pol observations, while the number of independent data could be $1.7 \mathrm{~N}$ as estimated using the Aquarius radar data [33]. A minimum of $N$ is deduced as 4.2 in order to facilitate a well-conditioned outcome $(1.7 N>N+3)$. In all the retrievals presented in the paper, $N$ is at least 5 . When the modification factor is let to vary in time $\left(f_{i}\right)$, a longer time-series is needed, or the constraint to the size of the temporal change was imposed.

\section{Data}

Multiple sets of data are used to evaluate the retrieval of VWC and surface roughness. Their details are listed in Table 1 and locations are shown in Figure 2. Truck-mounted radar observed four different types of bare surfaces in Ypsilanti, Michigan [34] over a two-month campaign at $1.26 \mathrm{GHz}$ and $40^{\circ}$ incidence angle. The surface roughness is time-invariant at each site, but changes from $0.55 \mathrm{~cm}$ to $3.5 \mathrm{~cm}$ from site to site. 

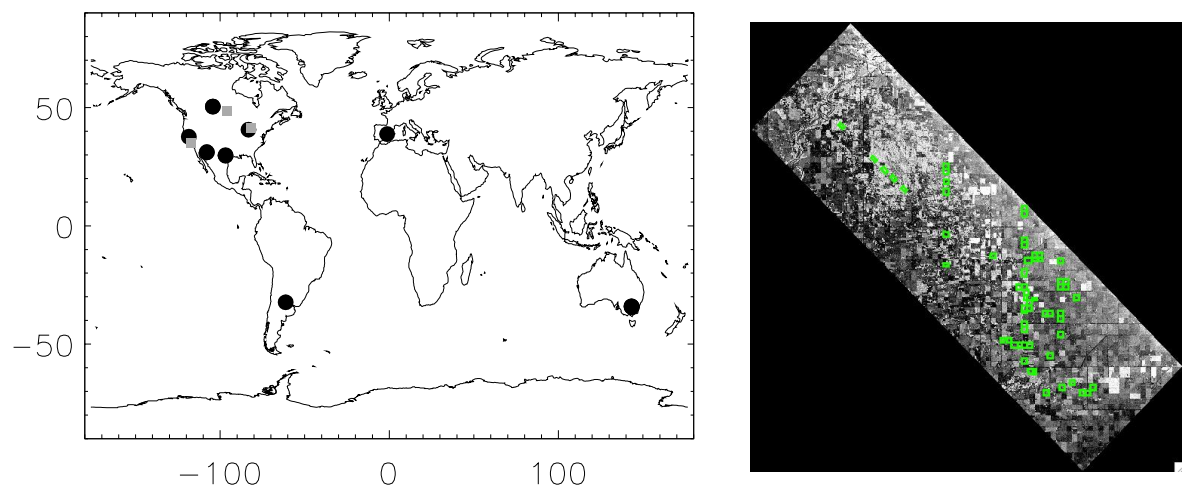

Figure 2. (left) locations of the 14 SMAP core validation sites (circle), and airborne/ground sites in California, Michigan, and Manitoba (grey square). Several SMAP sites are close to each other and appear as a single dot; (right) field locations from SMAPVEX12 campaign: green rectangles overlaid on $25 \times 60 \mathrm{~km}^{2}$ UAVSAR image.

Table 1. List of datasets.

\begin{tabular}{cccccc}
\hline & Michigan Tower & SGP99 & SMAPVEX12 & SJV & SMAP \\
\hline Spatial Resolution & NA & $\sim 800 \mathrm{~m}$ & $10 \mathrm{~m}$ & $10 \mathrm{~m}$ & $3 \mathrm{~km}$ \\
\# Time Series & 10 & 6 & 13 & 14 & $\sim 25$ \\
In situ roughness Availability & yes & yes & yes & yes & no \\
In situ VWC Availability & Not applicable & yes & yes & yes & no \\
Landcover & Bare soil & Pasture, & Pasture,wheat, \\
& & & soybean,corn, & Shrub & Wheat, \\
& & & canola & & Soybean \\
\hline
\end{tabular}

Airborne and ground measurements of natural pasture fields from the Southern Great Plains 1999 campaign (SGP99) offer scatterometer data in the Little Washita watershed region, Chichasha, Oklahoma, USA [35]. The airborne data were collected by the Passive/ Active L-band Sensor (PALS) scatterometer operating at $1.26 \mathrm{GHz}$ at the incidence angle centered at $38^{\circ}$. The in situ values of roughness, correlation length, and VWC (drying destructive samples) remain constant in time. Across 6 fields, surface roughness changed from 0.3 to $0.9 \mathrm{~cm}$, and VWC varied from 0.1 to $0.5 \mathrm{~kg} / \mathrm{m}^{2}$. With six time-series inputs spanning a 12-day period, the time-series retrieval was performed for each of the six fields.

The airborne UAVSAR (Uninhabited Aerial Vehicle Synthetic Aperture Radar) data from the Soil Moisture Active Passive Validation Experiment 2012 (SMAPVEX12) [36] provide high-resolution coverage of cropland over the entire growth stages of wheat, pasture, corn, soybean, and canola. SMAPVEX12 was conducted in Manitoba, Canada, over a 6-week period in 2012 offering 13 temporal repeat passes. The raw data were normalized to $40^{\circ}$ incidence angle using the histogram matching method; the root mean squared error (RMSE) of the normalization is smaller than $1 \mathrm{~dB}$ [36]. The speckle noise of the UAVSAR data at the raw multi-looked resolution of $7 \mathrm{~m}$ is $0.6 \mathrm{~dB}$. In this study, the data were averaged over a field of $800 \times 800 \mathrm{~m}^{2}$. The speckle noise almost vanishes during the average. Surface roughness was measured as follows. A 1-m long pinboard was placed in the north- and south-directions at least three locations per field. The slope was removed in the post processing. The readings of RMS height (six or more per field) were averaged to produce one in situ value. VWC values were measured through drying of destructive samples.

Another UAVSAR campaign mapped a shrub site in San Joaquin Valley (SJV), California, USA 17 times from June 2010 until August 2014 [28]. The local incidence angle of the test site was maintained at $36.5^{\circ}$ since the flights were a part of interferometry operations. The single-look data were averaged over an area of $1 \mathrm{~km} \times 400 \mathrm{~m}$. The variation of incidence angle within the domain was $\pm 1^{\circ}$. VWC varied 
from 0.1 to $0.6 \mathrm{~kg} / \mathrm{m}^{2}$ temporally, and the surface roughness of the natural land remained unchanged at $0.4 \mathrm{~cm}$.

The L-band SMAP satellite provided $\sigma^{0}$ at 3-km resolution with 2-3 days repeat intervals from 24 April 2015 to 7 July 2015 [24]. Following spatial multi-looking, the $\sigma^{0}$ values were produced at $1-\mathrm{km}$ spatial resolution. The total measurement error of $0.7 \mathrm{~dB}$ includes speckle, relative calibration, and residuals after correcting for terrestrial contamination. The results reported in this paper used version T12400 of the SMAP radar data (nearly identical to the validated release dated 30 April 2016) To facilitate the assessment of VWC and roughness retrieval, well-characterized sites (Core Validation Sites, CVS [37]) were selected. Although in situ measurements of VWC and roughness over the entire 3-km pixel are not feasible, synoptic description of their conditions is available from the site host.

\section{Results and Discussion}

\subsection{Surface Roughness Retrieval}

The retrievals over the Michigan bare surface were discussed in detail by Kim et al. [22] and presented with a scatter plot in Figure $3 \mathrm{a}$ and Table 2. The test site has an isotropic surface with no row structure, and is constructed to describe smooth to rough surfaces. The forward model that solved the Maxwell equation numerically has no approximation and was not tuned. The retrieval follows the observations closely with the correlation of 0.99 . The bias and RMSE are smaller than $25 \%$ of the signal. Although the number of retrievals is small, the high correlation leads to the very small $p$-value and high confidence.

With the airborne campaign over the six pasture fields (SGP99), the in situ roughness shows smooth surface with rms height smaller than $1 \mathrm{~cm}$. The retrievals also depict the surface as smooth with $\mathrm{rms}$ height $<1 \mathrm{~cm}$. The differences from the in situ are smaller than $50 \%$ of the signal in most cases except one field (Figure $3 \mathrm{~b}$ and Table 2). The outlier retrieval could improve to $0.85 \mathrm{~cm}$ (from the $1.4 \mathrm{~cm}$ ) if the bias offset ( $c$ in Equation (2)) is optimized manually. Because the outlier can be fixed by a retrieval algorithm, we have presented both retrievals by the two algorithms in Table 2, instead of applying statistical improvement such as bootstrapping. When the one outlier is excluded, the RMSE and correlation improve to 0.23 and 0.58 , respectively. Future studies may further confirm whether these changes to retrieval algorithm can be widely applied.

For the San Joaquin Valley (SJV) shrubland, the retrieved roughness of $1 \mathrm{~cm}$ consistently describes the land as relatively smooth surface as the in situ measurement of $0.4 \mathrm{~cm}$ does (Figure 3c). The roughness of natural land without tillage would be temporally stationary, and the retrieval was performed accordingly. The shrub plants are located randomly over a flat natural land (see photos in [28]), precluding any resonant scattering effects by soil or vegetation periodic rows.

In the SMAPVEX12 airborne campaign, surface roughness was measured for each field at least once during the entire crop growth period. Because the forward model was developed for each crop type, the retrieval performance is expected to depend on a crop type. The errors in terms of RMSE are $32 \%$ (wheat), $29 \%$ (soybean), $46 \%$ (corn), and $42 \%$ (canola) of the signal in terms of its rms (Figure $3 \mathrm{~d}-\mathrm{g}$ and Table 2). These statistics hint a larger difference as vegetation becomes thicker: the VWC of fully-grown corn and canola exceeds $5 \mathrm{~kg} / \mathrm{m}^{2}$, while soybean VWC does not exceed $\sim 1.5 \mathrm{~kg} / \mathrm{m}^{2}$ and wheat remains smaller than $5 \mathrm{~kg} / \mathrm{m}^{2}$. The correlation between in situ and retrieval portrays the similar pattern. The correlation for corn and canola is very weak (the high $p$-value is an indication of poor correlation and low confidence of the coefficient). The stronger scattering and absorption by thicker vegetation may pose greater challenges to accurate retrieval of the underlying soil property.

Periodic row structures were present in some of the farm fields of SMAPVEX12, unlike the cases of Michigan, SJV, and SGP99. Although the row structures on the soil surface were not built in the Canadian fields, the vegetation was planted at regular spacing. Constructive Bragg resonance as studied by Whitt and Ulaby [38] could occur. The Bragg resonance was not included in the forward 
model, and therefore its presence could result in retrieval errors. At a set of preferred incidence angle $(\theta)$, width of the row spacing perpendicular to the row $(w)$, and width in the SAR viewing direction $(d)$, the resonance may develop:

$$
d=m \lambda / \sin (\theta)=w / \sin (\phi)
$$

where $\phi$ is the azimuth angle between plant's row and SAR azimuth angle, $m$ is integer multiple, $\lambda$ is wavelength. UAVSAR flew and viewed the area in the direction of $45^{\circ}$ to the north. Therefore, $\phi$ is always $45^{\circ}$. The periodic plants have the directions of either north-south or east-west according to the limited survey in wheat, bean, and corn fields (marked by red color in Figure $3 \mathrm{~d}-\mathrm{f}$ ). The spacing $(w)$ between two rows of plants is $25 \mathrm{~cm}$ (wheat), and $75 \mathrm{~cm}$ (corn and soybean). It follows that the preferred $\theta$ is $42.3^{\circ}$ for $w$ of $75 \mathrm{~cm}\left(26.6^{\circ}\right.$ and $63.8^{\circ}$ are also feasible but these are at the edges of a scene and were not used during the analysis), and $42.3^{\circ}$ for $w$ of $25 \mathrm{~cm}$. Each field was imaged by UAVSAR at three different $\theta$ per day to facilitate the incidence angle normalization. The chances are small that the UAVSAR observes a field at $\sim 42.3^{\circ}$ out of its entire $\theta$ range of 25 to $60^{\circ}$ across swath. This prediction is corroborated by Figure $3 \mathrm{~d}-\mathrm{f}$ in that the retrievals (red colored) from the field with the periodic structure do not show distinctively different retrieval performance.

One static surface roughness value was retrieved per each pixel over the 2.5 months period of SMAP observation at $3 \mathrm{~km}$ pixel. Since in situ measurements of roughness over the entire $3 \mathrm{~km}$ pixel are not feasible, quantitative evaluation is not performed in Table 3. Nonetheless-

- $\quad$ First, we examine various properties of the retrieval for soundness. The retrieved values range from $0.5 \mathrm{~cm}$ to $4 \mathrm{~cm}$, which are realistic within the range for isotropic surfaces. To the extent that the changes to $\sigma^{0}$ by terrain slope within $3-\mathrm{km}$ pixel are temporally static, they are corrected by the bias correction ( $c$ in Equation (2)) and the scattering may represent those from the isotropic surfaces. Considering the departure of the surface condition from the isotropic assumption, the SMAP retrievals are more likely to be an effective roughness.

- Second, there is a general trend towards rougher surfaces in croplands, suggesting the impacts by farming operations on soil surfaces. The mean of the retrieved roughness is $2.6 \mathrm{~cm}$ (cropland) and $1.5 \mathrm{~cm}$ (natural terrain).

- An interesting case is found in the Monte Buey site, cropland with mostly soybeans in central Argentina. After day 160 (9 June), $\sigma^{0}$ suddenly decreased (Figure 4). According to the ground observation, a harvest ended around day 153 with surface roughness having changed during the harvest. Additional experiments were performed: soil moisture, VWC and surface roughness were retrieved for two separate periods: before and after the harvest. After the harvest, the surface roughness increased (from $2.15 \mathrm{~cm}$ to $2.47 \mathrm{~cm}$ ) and VWC is reduced (VWC factor, $f$, changing from 0.3 to 0.05 ), which are consistent with the expectation of post-harvest conditions.

Table 2. Evaluation statistics of surface roughness retrieval in $\mathrm{cm}$, shown in Figure 3. $\left(^{*}\right)$ the outlier is the result of automated unsupervised estimate and is correctable through supervision. $p$-value $[0,1]$ quantifies a probability of occurrence of the null hypothesis that the correlation results from random variables.

\begin{tabular}{cccccc}
\hline Landcover & RMS of Measured Signal & Bias & RMSE & \multicolumn{2}{c}{ Correlation } \\
\cline { 3 - 6 } & & & & Coefficient & $p$-Value \\
Bare & 2.04 & 0.12 & 0.49 & 0.99 & 0.006 \\
Pasture & 0.53 & $0.16(-0.02)$ & $0.53(0.23)$ & $-0.004(0.58)$ & $0.994(0.303)$ \\
(if excluding outlier *) & 1.20 & 0.036 & 0.39 & 0.54 & 0.105 \\
Wheat & 0.98 & 0.16 & 0.28 & 0.035 & 0.16 \\
Bean & 1.37 & 0.034 & 0.63 & -0.16 & 0.42 \\
Corn & 1.17 & 0.25 & 0.50 & -0.479 \\
\hline
\end{tabular}


(a) bare

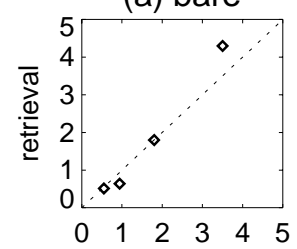

(e) bean

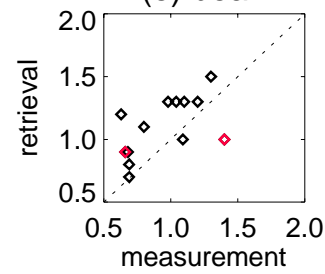

(b) pasture

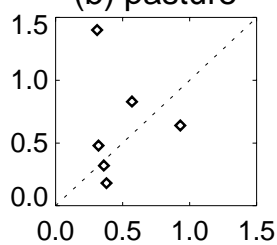

(f) corn

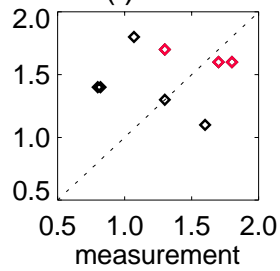

(c) shrub

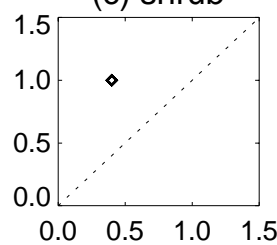

(g) canola

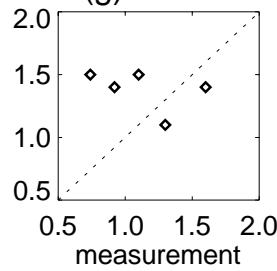

Figure 3. Validation of roughness retrievals (in $\mathrm{cm}$ ) from the field campaigns (a) bare surface of Michigan Tower [22]; (b) SGP99; (c) SJV (only one datum); (d-g) SMAPVEX12. Each datum represents one time-invariant estimate of roughness using time-series observations of $\sigma^{0}$ at individual spatial fields. Colored in red in (d-f) are associated with the presence of observed exit periodic row structure of vegetation. The quantitative values are shown in Table 2.

Table 3. Surface roughness retrieval in $\mathrm{cm}$ using 3-km SMAP data. Mean and standard deviation of the retrieved roughness are $2.6 \pm 1.2 \mathrm{~cm}$ (cropland); $1.5 \pm 0.81 \mathrm{~cm}$ (noncrop land).

\begin{tabular}{|c|c|c|c|c|c|c|c|c|}
\hline Cropland & $\begin{array}{c}\text { St. } \\
\text { Josephs }\end{array}$ & Kenaston 1 & Kenaston2 & $\begin{array}{c}\text { Monte } \\
\text { Buey }\end{array}$ & Valencia & Yanco1 & & \\
\hline Retrieval & 3.1 & 1.3 & 1.2 & 2.1 & 3.9 & 3.7 & & \\
\hline $\begin{array}{l}\text { Noncrop } \\
\text { land }\end{array}$ & $\begin{array}{l}\text { Walnut } \\
\text { Gulch1 } \\
\text { grass }\end{array}$ & $\begin{array}{l}\text { TxSON1 } \\
\text { savanna }\end{array}$ & $\begin{array}{l}\text { TxSON2 } \\
\text { savanna }\end{array}$ & $\begin{array}{c}\text { Yanco2 } \\
\text { grass }\end{array}$ & $\begin{array}{c}\text { Yanco3 } \\
\text { grass }\end{array}$ & $\begin{array}{c}\text { Yanco4 } \\
\text { grass }\end{array}$ & $\begin{array}{c}\text { Walnut } \\
\text { Gulch2 } \\
\text { shrub }\end{array}$ & $\begin{array}{c}\text { Tonzi } \\
\text { woody } \\
\text { savanna }\end{array}$ \\
\hline Retrieval & 1.7 & 2.0 & 1.4 & 2.0 & 1.9 & 0.34 & 0.26 & 2.5 \\
\hline
\end{tabular}

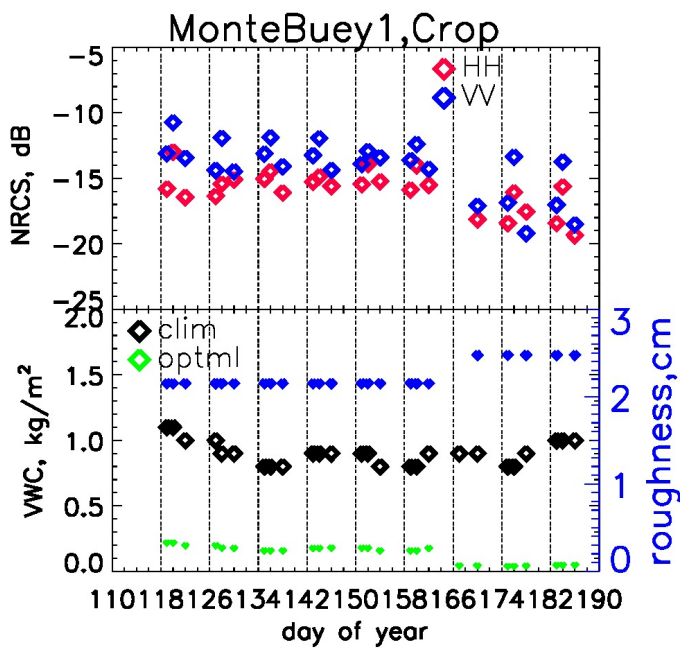

Figure 4. Retrievals of VWC and roughness at the Monte Buey site using SMAP data in 2015. clim and optml refer to VWC values from climatology and optimized (=retrieval).

\subsection{VWC Retrieval}

Minor variations to the cost function of Equation 2 were experimented, as mentioned in Section 2. For the SGP99 field campaign, the minimization strategy was to optimize the bias correction $(c$ in 
Equation (1)), which reflects that the forward model may not simulate the number of plants correctly. Consequently the VWC modification factor $(f)$ was set to 1 , and VWC was not retrieved. Minimization could also be possible with keeping $c$ to 0 and estimating $f$, which was not tested.

\subsubsection{SMAPVEX12}

Over the SMAPVEX12 croplands where the plants grew significantly, $f_{i}$ is let to vary dynamically while $c$ is held constant. The rationale of this arrangement is that the details of the vegetation such as the number of the plants were measured comprehensively during the field work, and the forward models were developed to match UAVSAR $\sigma^{0}$ (through physical modeling such as the modeling of coherent scattering [27] or multiple scattering [29]). Then, the need for the bias correction is diminished. By acknowledging that plant growth is steady, VWC is allowed to change up to 1.25 times of the retrieved value at the previous time step during the soybean growth [27], and up to pre-defined values for the other respective crops. For corn, VWC increases with time except the very late stage of growth cycle.

The retrievals shown in Figure 5 generally follow the in situ reference despite challenging conditions. First, even for the dense vegetation such as corn and canola where VWC reaches $4 \mathrm{~kg} / \mathrm{m}^{2}$ and $8 \mathrm{~kg} / \mathrm{m}^{2}$, respectively, the retrievals show good agreement with the in situ. Second, the crop VWC of SMAPVEX12 varies significantly from near zero (seeding) to the maximum (fully grown plants), and the retrievals follow the temporal variations. The RMSE of the all fields in the scatter plot is smaller than $20 \%$ of the maximum range of in situ VWC for all the crops. The correlation ranges from 0.57 to 0.91 . Further details of discrepancy between retrieval and in situ VWC are analyzed below.

A possible reason for the low correlation coefficients of VWC retrieval of the wheat field (Figure $5 b$ ) is that surface and double-bounce scattering generally dominate among the three scattering terms (Table 4; Kenaston case in Figure 7 of [24]; Figure 7 of [39]). Thus, $\sigma^{0}$ is more sensitive to soil moisture and rms height than VWC. In comparison, for canola (Figure $5 \mathrm{~h}$ ), volume and double-bounce scattering generally dominate (Table 4; Figure 8 of [39]). Then, the correlation coefficient of retrieval and reference is high as shown in Figure 5. Accordingly for canola, the soil moisture retrieval results are not as good as those for wheat and soybean. For soybean fields, all three of the scattering mechanisms can be dominant (Table 4; Figures 10 and 13 of [40]).

Table 4. Decomposition of modeled total $\sigma^{0}$ into scattering mechanism at specified levels of VWC and soil moisture $\left(M_{\mathrm{V}}\right)$ using SMAPVEX12 data. The coherent model for soybean does not distinguish double-bounce from volume scattering. For brevity, only the cases for $\mathrm{HH}$ are tabulated.

\begin{tabular}{|c|c|c|c|c|c|c|}
\hline & \multicolumn{2}{|c|}{ Wheat HH } & \multicolumn{2}{|c|}{ Canola HH } & \multicolumn{2}{|c|}{ Soybean $\mathbf{H H}$} \\
\hline Surface $(\mathrm{dB})$ & -20.8 & -20.0 & -25.3 & -18.1 & -26.1 & -27.4 \\
\hline Double bounce (dB) & -19.4 & -18.4 & -16.8 & -13.1 & -280 & \\
\hline Volume $(\mathrm{dB})$ & -41.3 & -41.3 & -17.1 & -14.1 & -28.0 & -19.0 \\
\hline at $\operatorname{VWC}\left(\mathrm{kg} / \mathrm{m}^{2}\right)$ & 1.5 & 2.3 & 1.9 & 8.0 & 0.10 & 0.54 \\
\hline at $M_{\mathrm{v}}\left(\mathrm{m}^{3} / \mathrm{m}^{3}\right)$ & \multicolumn{2}{|c|}{0.2} & \multicolumn{2}{|c|}{0.25} & \multicolumn{2}{|c|}{0.25} \\
\hline
\end{tabular}

The VWC retrieval for canola field 115 shows large difference (Figure $5 \mathrm{~g}$ ). The evaluation of the forward model for field 115 shows that from 29 June to 10 July, the modeled $\mathrm{HH}$ is much smaller than the measured HH (Figure 6). For canola, HH decreases with VWC because the increasing vegetation enhances the absorption. The retrieval attempted to reduce VWC to obtain the high value of modeled $\mathrm{HH}$ to match the observation, resulting in the retrieved VWC being too low.

The scatter plot for soybean shows a large error towards high VWC (Figure 5d). These originate in field 51 during the later crop development days. The evaluation of the forward model of $\sigma^{0}$ for field 51 in Figure 7 shows that the forward model does not simulate the observation well when the VWC is high. Accordingly, the VWC retrieval of field 51 became too low for large VWC cases. Another possible reason is that the surface roughness retrieval was too large by $50 \%$ for field 51 . The combination of 
large rms height and low VWC (resulting in large surface scattering) can have a comparable $\sigma^{0}$ as that of small rms height and large VWC (resulting in large vegetation scattering). As the retrieval can choose either of the two combinations, the estimates of rms height and VWC can be both subject to errors. The constraints were implemented during the retrieval to avoid the ambiguity (time-invariant roughness and temporal continuity of VWC), which worked well on the other sites but not on field 51.

Overall, these results demonstrate that the forward model inversion has a potential to retrieve VWC in most instances for the four major crops over the entire phase of the crop growth.
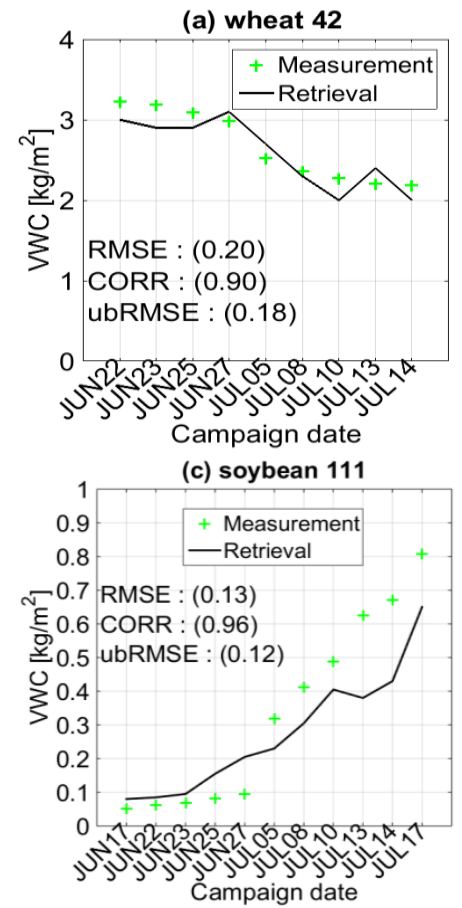

(e) corn 83

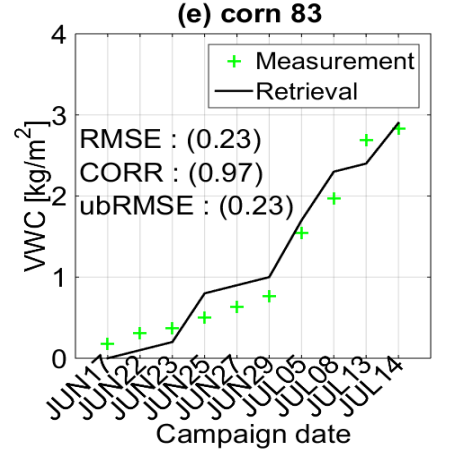

(g) canola 115

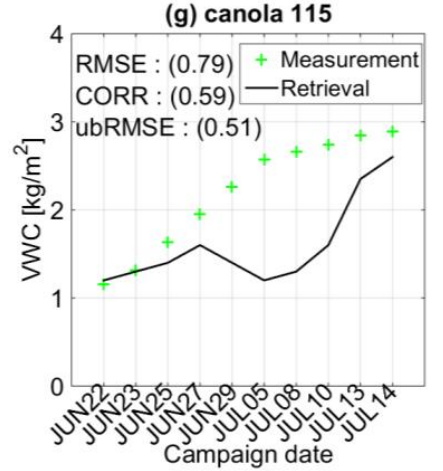

(b) wheat-all

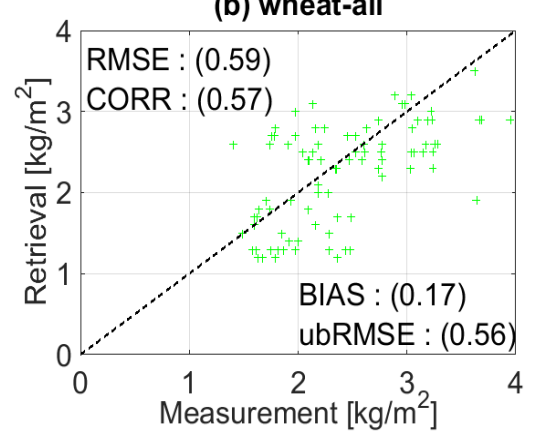

(d) soybean-all

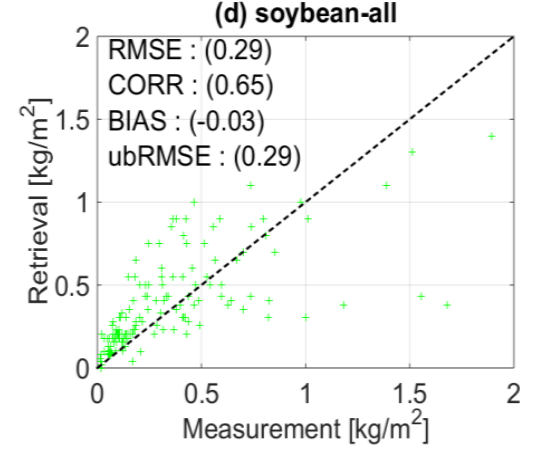

(f) corn-all

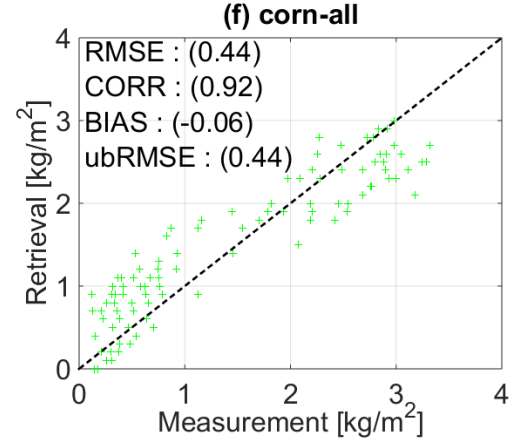

(h) canola-all

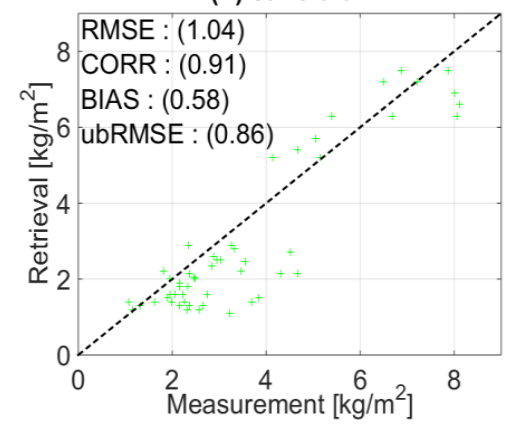

Figure 5. Retrievals of VWC using SMAPVEX12 data at one field (the field number is shown on the title) and over all the fields. The corn results are from [29]. 


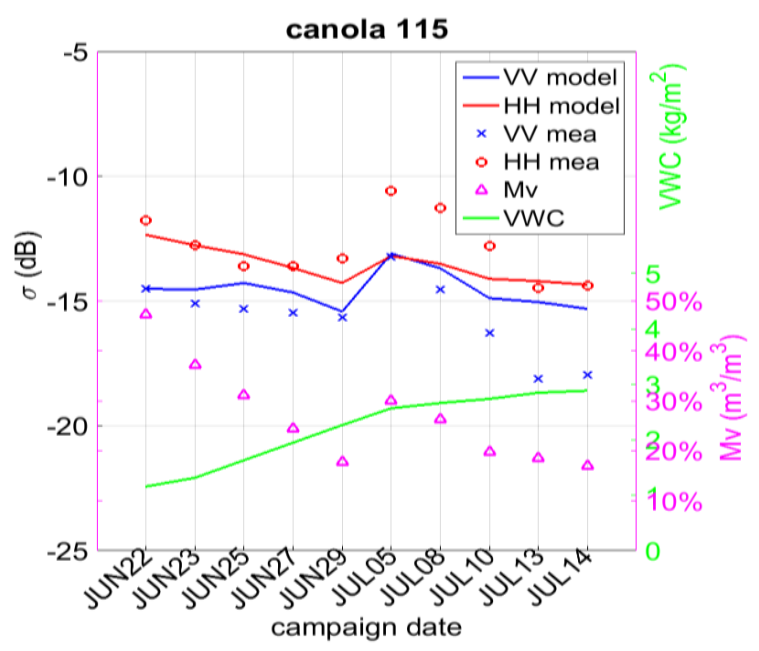

Figure 6. Forward model evaluation for canola field 115. Mv and VWC refers to in situ data. mea denotes in situ measurement.

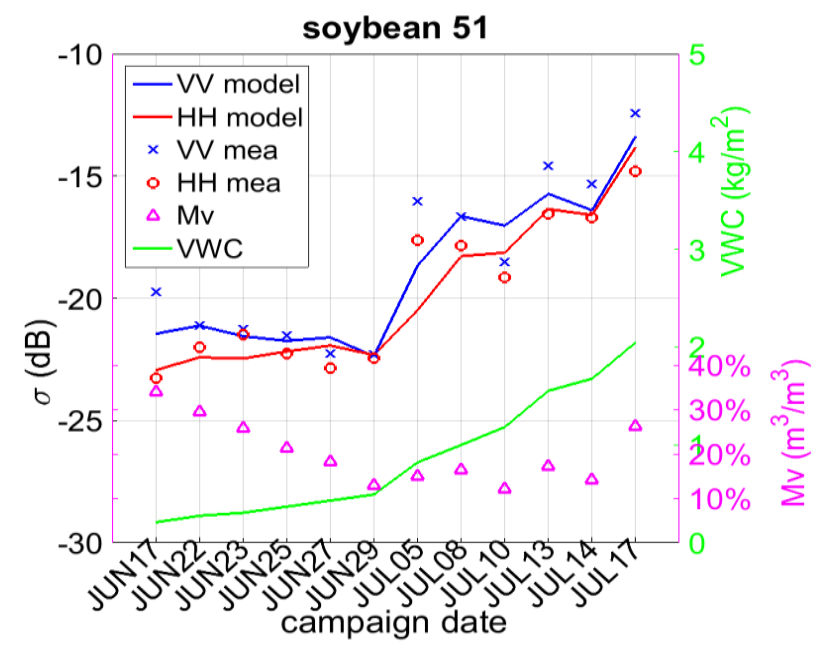

Figure 7. Forward model evaluation for soybean field 51.

\subsubsection{SMAP}

The VWC using the 3-km resolution SMAP $\sigma^{0}$ was retrieved by estimating the bias correction $(c$ in Equation (1)) and one static modification factor over the entire time series $(f)$ instead of the temporal variation version $\left(f_{i}\right)$ used for the UAVSAR. The rationale was to reduce the degrees of freedom in the inversion system and to prevent an ill-posed condition. This need is particularly important considering spatial representativeness and fidelity of a forward model. First, regarding the representativeness, a dominant landcover type was identified for each $3-\mathrm{km}$ pixel in terms of areal cover extent and subsequently a matching forward model was selected for retrieval. Therefore, when subpixel heterogeneity exists, the retrieval would be subject to error. Second, about the fidelity, the forward models were developed using airborne and ground data such as SGP99 an SMAPVEX12 data, and the global application would introduce error.

For soil moisture retrieval, the use of $c$ and static $f$ per each pixel was effectively [24]. The retrievals of VWC are presented in Figure 8 and $f$ are tabulated in Table 5. Comparison is made with the first guess (the MODIS-derived climatology) and also with the contemporary VWC (derived with the contemporary 16-daily MODIS data of 2015 using the same algorithm as applied to the climatology). 
- In about half of the cases, the search of the minimum cost did not require the revision of the climatology VWC. A few cases exhibit seemingly a large revision, but in fact the revision is not significant. As the first example, the significant reductions in Yanco 3-4 are warranted. The climatology VWC reaches up to $1 \mathrm{~kg} / \mathrm{m}^{2}$, which is too large for natural grassland. The 2015 MODIS data also predict small VWC (the VWC is set to zero in Figure 8 because the NDVI (normalized difference vegetation index) is -0.3 : typically, NDVI smaller than 0.1 is associated with bare surface or rocks). The grassland VWC measured in the SGP99 campaign ranged from 0.1 to $0.5 \mathrm{~kg} / \mathrm{m}^{2}$ only [41]. The second example is Walnut Gulch1. Although the size of $f$ is large, this represents only a small revision from 0.2 to $0.1 \mathrm{~kg} / \mathrm{m}^{2}$.

- In Yanco 2, both the climatology and 2015 observation produce VWC of $\sim 0.5 \mathrm{~kg} / \mathrm{m}^{2}$, while the SMAP retrieval is smaller than $0.2 \mathrm{~kg} / \mathrm{m}^{2}$. Possible errors in landcover classification may be the reason. Although the MODIS-based landcover database (mcd12q1) describes Yanco 2 as grassland, close examination indicates that the area is likely a cropland similar to Yanco 1. Because the forward models for grass vegetation were selected for this site and applied for retrieval, an error in retrieved VWC is anticipated. In the future, the forward model of crop vegetation will be tested on Yanco 2.

- In the Monte Buey site, where a harvest ended around day 153, VWC is reduced with $f$ changing from 0.3 to 0.05 (Figure 4). This is consistent with the expectation of post-harvest conditions. For this site, $f$ was estimated for two separate time windows unlike the other sites where only one $f$ was estimated.

- $\quad$ The magnitude of the retrieved VWC in Monte Buey is only $20 \%$ of the climatology. A potential cause is that the forward model does not simulate the large undulations in $\sigma^{0}$ associated with the effects by periodic crop rows (Figure 4). The minimization of the cost function could have lowered the retrieved VWC to best match the SMAP data. As a separate matter, why the 2015 VWC is so large and why it does not capture the effect of the harvest are unclear. An explanation may be that the conversion from NDVI to VWC is one formula regardless of the crop type, which may not be suitable for the dominant bean crop of the site.

- In St. Josephs, the retrieved VWC is larger than the climatology, and the retrieval matches the 2015 VWC well. In Yanco1, the retrieval revises the climatology to the lower VWCs. The reduction is consistent with the comparison that the 2015 VWC is smaller than the climatology. However such consistency is not found in Kenaston 2.

- The revision factor $f$ is larger for croplands than non-croplands if the above rectification for the Yanco 2-4 and Walnut Gulch1 sites is taken into account. This agrees with the expectation because croplands experience large interannual changes and the climatology VWC ancillary may need revision.

Table 5. VWC retrieval using SMAP data, presented in terms of the modification factor, $f$ in $\%$. The values are consistent with the plots shown in Figure 8.

\begin{tabular}{ccccccccc}
\hline Cropland & St. Josephs & Kenaston 1 & Kenaston 2 & $\begin{array}{c}\text { Monte } \\
\text { Buey }\end{array}$ & Valencia & Yanco1 & & \\
\hline Retrieval & $+20 \%$ & 0 & $-50 \%$ & $-80 \%$ & 0 & $-80 \%$ & & Tonzi \\
Non & Walnut & TxSON1 & TxSON2 & Yanco2 & Yanco3 & Yanco4 & Walnut & Ton \\
cropland & Gulch1 grass & savanna & savanna & grass & grass & grass & Gulch2 shrub & woody savanna \\
Retrieval & $-50 \%$ & 0 & 0 & $-70 \%$ & $-90 \%$ & $-95 \%$ & 0 & 0 \\
\hline
\end{tabular}

The above assessment indicates that the SMAP retrieval of VWC offers a sensible outcome. Further validation may be achieved in the future by comparing with the coarse-resolution VWC derived with the radiometer data. 

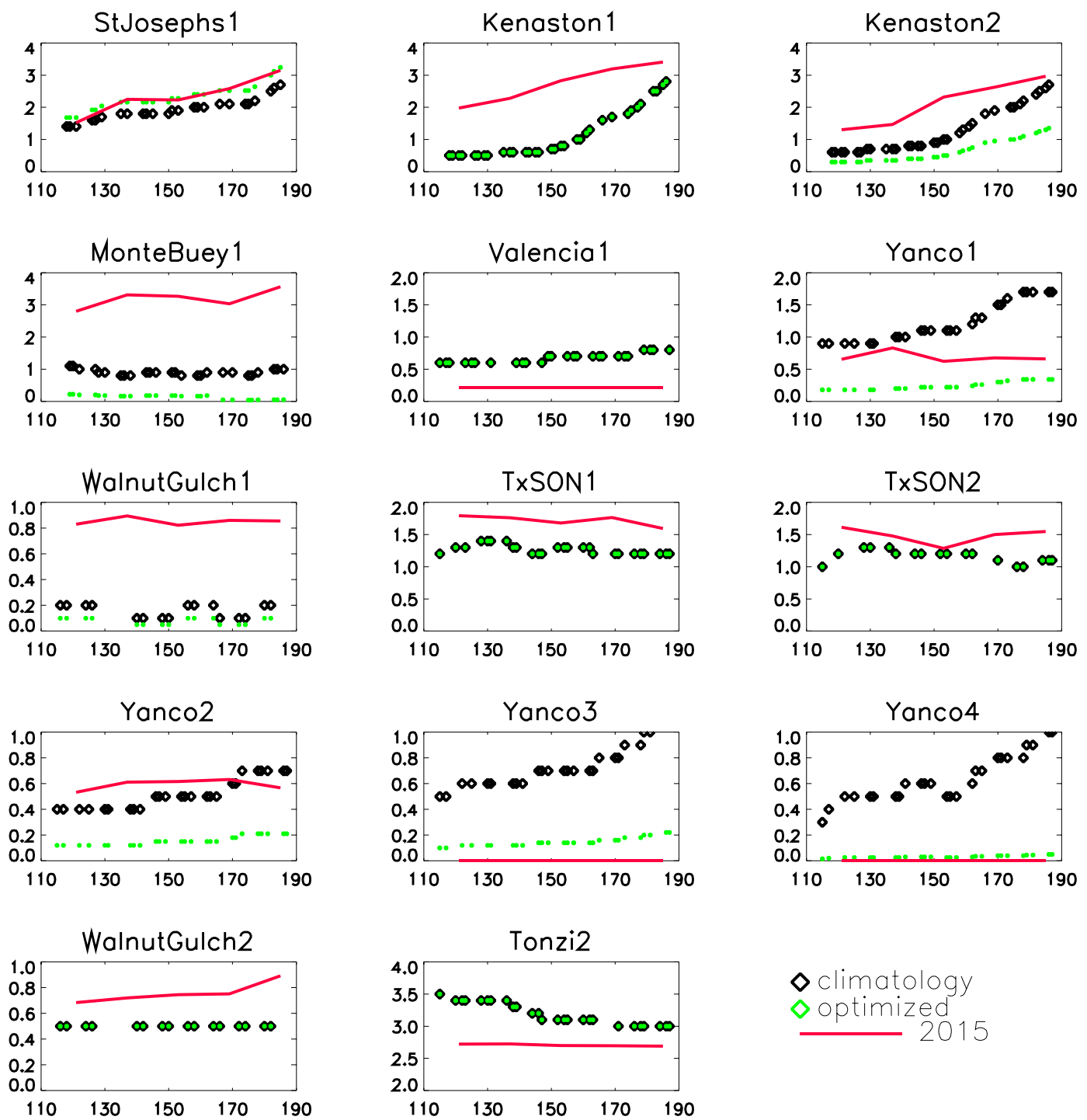

Figure 8. Retrievals of VWC using SMAP data in 2015 at core validation sites. climatology and optimized refer to VWC values from climatology and retrieval, respectively. Abscissa is the day of year. 2015 refers to the VWC derived using 16-daily MODIS data of the SMAP dates in 2015.

\section{Conclusions}

Soil surface roughness and vegetation water content (VWC) are estimated by inverting the physical models. The validation of the roughness estimates shows an accuracy of $25 \%$ (bare surface) and 29 to $46 \%$ (croplands and pasture). The correlation degrades as vegetation becomes thicker, indicating the stronger scattering and absorption by thicker vegetation. The roughness retrievals with the SMAP data are within the physical range of 0.5 to $4 \mathrm{~cm}$. They show larger values in croplands than in natural terrain. The VWC retrievals correctly follow the full growth of crops and the RMSE is smaller than $20 \%$ in the airborne data: the correlation ranges from 0.57 to 0.91 . The VWC retrievals from the SMAP data revised the climatology first guess more in the croplands where the climatology is more likely to depart from the contemporaneous condition, than in natural landcover.

These results suggest that the forward model and retrieval algorithms are sufficiently reliable to allow the estimates of soil moisture, soil surface roughness, and VWC in many sites tested. The possible merits of the findings are as follows. Surface roughness at the satellite footprint scale is difficult to characterize by in situ, ancillary, and non-microwave remote sensing because of the vegetation 
scattering and absorption. The optically-derived VWC database are subject to the saturation of leaf greenness towards high VWC. The approach presented here allows the retrieval of surface roughness and VWC at SAR spatial scale. Such capability may be useful for studies of climate, agriculture, and soil moisture retrieval.

Acknowledgments: Discussions with Aaron Berg, Michael Cosh, Marc Thibeault were very helpful. Valuable comments from the reviewers greatly improved the quality of the manuscript. This research was carried out at the Jet Propulsion Laboratory, California Institute of Technology (City, USA) under a contract with NASA.

Author Contributions: S.-B.K. conceived, conducted the experiments, and wrote the paper. H.H. and T.-H.L. performed the UAVSAR experiments. A.C. prepared SMAP data.

Conflicts of Interest: The authors declare no conflict of interest. The founding sponsors had no role in the design of the study; in the collection, analyses, or interpretation of data; in the writing of the manuscript, and in the decision to publish the results.

\section{References}

1. Friesen, J.C.; Steele-Dunne, S.C.; van de Giesen, N. Diurnal differences in global ERS backscatter. IEEE Trans. Geosci. Remote Sens. 2012, 50, 2595-2602. [CrossRef]

2. Oki, T.; Kanae, S. Global hydrological cycles and world water resources. Science 2006, 313, $1068-1072$. [CrossRef] [PubMed]

3. Schlesinger, W.H.; Jasechko, S. Transpiration in the global water cycle. Agric. For. Meteorol. 2014, 189, $115-117$. [CrossRef]

4. McNairn, H.; Boisvert, J.; Major, D.; Gwyn, G.; Brown, R.; Smith, A. Identification of agricultural tillage practices from C-band radar backscatter. Can. J. Remote Sens. 1996, 22, 154-163. [CrossRef]

5. Azzari, G.; Lobell, D.B. Satellite-based classification of tillage practices in the US. In Proceedings of the AGU Fall meeting, New Orleans, LA, USA, 11-15 December 2017.

6. Jackson, T.J.; Schmugge, T.J.; Wang, J.R. Passive microwave sensing of soil moisture under vegetation canopies. Water Resour. Res. 1982, 18, 1137-1142. [CrossRef]

7. Attema, E.; Ulaby, F.T. Vegetation modeled as a water cloud. Radio Sci. 1978, 13, 357-364. [CrossRef]

8. Pierdicca, N.; Pulvirenti, L.; Bignami, C. Soil moisture estimation over vegetated terrains using multitemporal remote sensing data. Remote Sens. Environ. 2010, 114, 440-448. [CrossRef]

9. Theis, S.W.; Blanchard, B.J.; Blanchard, A.J. Utilization of active microwave roughness measurements to improve passive microwave soil-moisture estimates over bare soils. IEEE Trans. Geosci. Remote Sens. 1986, 24, 334-339. [CrossRef]

10. Konings, A.G.; Piles, M.; Rotzer, K.; Chan, S.T.K.; McColl, K.A.; Entekhabi, D. Vegetation optical depth and scattering albedo retrieval using time series of dual-polarized L-band radiometer observations. Remote Sens. Environ. 2016, 172, 178-189. [CrossRef]

11. Calvet, J.C.; Wigneron, J.P.; Walker, J.; Karbou, F.; Chanzy, A.; Albergel, C. Sensitivity of passive microwave observations to soil moisture and vegetation water content: L-band to W-band. IEEE Trans. on Geosci. Remote Sens. 2011, 49, 1190-1199. [CrossRef]

12. Fernandez-Moran, R.; Al-Yaari, A.; Mialon, A.; Mahmoodi, A.; al Bitar, A.; de Lannoy, G.; Rodriguez-Fernandez, N.; Lopez-Baeza, E.; Kerr, Y.; Wigneron, J.-P. SMOS-IC: An alternative SMOS soil moisture and vegetation optical depth product. Remote Sens. 2017, 9, 21. [CrossRef]

13. Wigneron, J.P.; Parde, M.; Waldteufel, P.; Chanzy, A.; Kerr, Y.; Schmidl, S.; Skou, N. Characterizing the dependence of vegetation model parameters on crop structure, incidence angle, and polarization at L-band. IEEE Trans. Geosci. Remote Sens. 2004, 42, 416-425. [CrossRef]

14. Santi, E.; Paloscia, S.; Pampaloni, P.; Pettinato, S.; Nomaki, T.; Seki, M.; Sekiya, K.; Maeda, T. Vegetation water content retrieval by means of multifrequency microwave acquisitions from AMSR2. IEEE J. Sel. Top. Appl. Earth Observ. Remote Sens. 2017, 10, 3861-3873. [CrossRef]

15. Parrens, M.; Wigneron, J.P.; Richaume, P.; Mialon, A.; al Bitar, A.; Fernandez-Moran, R.; Al-Yaari, A.; Kerr, Y.H. Global-scale surface roughness effects at L-band as estimated from SMOS observations. Remote Sens. Environ. 2016, 181, 122-136. [CrossRef] 
16. Hunt, E.R.; Li, L.; Yilmaz, M.T.; Jackson, T.J. Comparison of vegetation water contents derived from shortwave-infrared and passive-microwave sensors over central Iowa. Remote Sens. Environ. 2011, 115, 2376-2383. [CrossRef]

17. Kim, Y.; Jackson, T.J.; Bindlish, R.; Lee, H.Y.; Hong, S.Y. Radar vegetation index for estimating the vegetation water content of rice and soybean. IEEE Geosci. Remote Sens. Lett. 2012, 9, 564-568.

18. Arii, M.; van Zyl, J.J.; Kim, Y. A general characterization for polarimetric scattering from vegetation canopies. IEEE Trans. Geosci. Remote Sens. 2010, 48, 3349-3357. [CrossRef]

19. Balenzano, A.; Mattia, F.; Satalino, G.; Davidson, M.W.J. Dense temporal series of C- and L-band SAR data for soil moisture retrieval over agricultural crops. IEEE J. Sel. Top. Appl. Earth Observ. Remote Sens. 2011, 4, 439-440. [CrossRef]

20. Pathe, C.; Wagner, W.; Sabel, S.; Doubkova, M.; Basara, J.B. Using ENVISAT ASAR Global Mode data for surface soil moisture retrieval over Oklahoma, USA. IEEE Trans. Geosci. Remote Sens. 2009, 47, 468-480. [CrossRef]

21. Dubois, P.C.; van Zyl, J.J.; Engman, E.T. Measuring soil moisture with imaging radars. IEEE Trans. Geosci. Remote Sens. 1995, 33, 915-926. [CrossRef]

22. Kim, S.B.; Tsang, L.; Johnson, J.T.; Huang, S.; van Zyl, J.J.; Njoku, E.G. Soil moisture retrieval using time-series radar observations over bare surfaces. IEEE Trans. Geosci. Remote Sens. 2012, 50, 1853-1863. [CrossRef]

23. Oh, Y.; Sarabandi, K.; Ulaby, F.T. An empirical model and an inversion technique for radar scattering from bare soil surfaces. IEEE Trans. Geosci. Remote Sens. 1992, 30, 370-382. [CrossRef]

24. Kim, S.B.; van Zyl, J.J.; Johnson, J.T.; Moghaddam, M.; Tsang, L.; Colliander, A.; Dunbar, R.S.; Jackson, T.K.; Jaruwatanadilok, S.; West, R.; et al. Surface soil moisture retrieval using the L-band synthetic aperture radar onboard the Soil Moisture Active Passive (SMAP) satellite and evaluation at core validation sites. IEEE Trans. Geosci. Remote Sens. 2017, 55, 1897-1914. [CrossRef]

25. Kim, S.B.; Moghaddam, M.; Tsang, L.; Burgin, M.; Xu, X.; Njoku, E.G. Models of L-band radar backscattering coefficients over the global terrain for soil moisture retrieval. IEEE Trans. Geosci. Remote Sens. 2014, 52, 1381-1396. [CrossRef]

26. Tabatabaeenejad, A.; Burgin, M.; Moghaddam, M. Potential of L-band radar for retrieval of canopy and subcanopy parameters of boreal forests. IEEE Trans. Geosci. Remote Sens. 2012, 50, 2150-2160. [CrossRef]

27. Huang, H.T.; Kim, S.B.; Tsang, S.; Xu, X.L.; Liao, T.H.; Jackson, T.J.; Yueh, S.H. Coherent model of L-band radar scattering by soybean plants: Model development, validation and retrieval. IEEE J. Sel. Top. Appl. Earth Observ. Remote Sens. 2016, 9, 272-284. [CrossRef]

28. Kim, S.B.; Arii, M.; Jackson, T.J. Modeling L-band synthetic aperture radar observations through dielectric changes in soil moisture and vegetation over shrublands. J. Sel. Top. Appl. Earth Observ. Remote Sens. 2017. [CrossRef]

29. Liao, T.H.; Kim, S.B.; Tan, S.; Tsang, S.; Su, C.X.; Jackson, T.J. Multiple scattering effects with cyclical terms in active remote sensing of vegetated surface using vector radiative transfer theory. IEEE J. Sel. Top. Appl. Earth Observ. Remote Sens. 2016, 9, 1414-1429. [CrossRef]

30. Lang, R.H.; Sidhu, J.S. Electromagnetic backscattering from a layer of vegetation: A discrete approach. IEEE Trans. Antenn. Propag. 1983, 1, 62-71. [CrossRef]

31. Huang, S.; Tsang, L.; Njoku, E.G.; Chen, K.S. Backscattering coefficients, coherent reflectivities, emissivities of randomly rough soil surfaces at L-band for SMAP applications based on numerical solutions of Maxwell equations in three-dimensional simulations. IEEE Trans. Geosci. Remote Sens. 2010, 48, 2557-2567. [CrossRef]

32. Burgin, M.; Clewley, D.; Lucas, R.; Moghaddam, M. A generalized radar backscattering model based on wave theory for multilayer multispecies vegetation. IEEE Trans. Geosci. Remote Sens. 2011, 49, 4832-4845. [CrossRef]

33. Konings, A.G.; McColl, K.A.; Piles, M.; Entekhabi, D. How many parameters can be maximally estimated from a set of measurements? IEEE Geosci. Remote Sens. Lett. 2015, 12, 1081-1085. [CrossRef]

34. Oh, Y.; Sarabandi, K.; Ulaby, F.T. Semi-empirical model of the ensemble-averaged differential Mueller matrix for microwave backscattering from bare soil surfaces. IEEE Trans. Geosci. Remote Sens. 2002, 40, 1348-1355. [CrossRef]

35. Jackson, T.J.; Hsu, A.Y. Soil moisture and TRMM microwave imager relationships in the Southern Great Plains 1999 (SGP99) experiment. IEEE Trans. Geosci. Remote Sens. 2001, 39, 1632-1642. [CrossRef] 
36. McNairn, H.; Jackson, T.J.; Wiseman, G.; Belair, S.; Bullock, P.; Colliander, A.; Cosh, M.H.; Kim, S.-B.; Magagi, R.; Moghaddam, M.; et al. The Soil Moisture Active Passive Validation Experiment 2012 (SMAPVEX12): Pre-launch calibration and validation of the SMAP Satellite. IEEE Trans. Geosci. Remote Sens. 2015, 53, 2784-2801. [CrossRef]

37. Colliander, A.; Jackson, T.J.; Bindlish, R.; Chan, S.; Das, N.; Kim, S.B.; Cosh, M.B.; Dunbar, R.S.; Dang, L.; Pashaian, L.; et al. Validation of SMAP surface soil moisture products with core validation sites. Remote Sens. Environ. 2016, 191, 215-231. [CrossRef]

38. Whitt, M.W.; Ulaby, F.T. Radar response of periodic vegetation canopies. Int. J. Remote Sens. 1994, 15, 1813-1848. [CrossRef]

39. Toure, A.; Thomson, K.P.B.; Edwards, G.; Brown, R.J.; Brisco, B.G. Adaptation of the MIMICS backscattering model to the agricultural context-Wheat and canola at L and C bands. IEEE Trans. Geosci. Remote Sens. 1994, 32, 47-61. [CrossRef]

40. Chiu, T.; Sarabandi, K. Electromagnetic scattering from short branching vegetation. IEEE Trans. Geosci. Remote Sens. 2000, 38, 911-925. [CrossRef]

41. Jackson, T.J.; le Vine, D.M.; Hsu, A.Y.; Oldak, A.; Starks, P.J.; Swift, C.T.; Isham, J.D.; Haken, M. Soil moisture mapping at regional scales using microwave radiometry: The Southern Great Plains hydrology experiment. IEEE Trans. Geosci. Remote Sens. 1999, 37, 2136-2151. [CrossRef]

(C) 2018 by the authors. Licensee MDPI, Basel, Switzerland. This article is an open access article distributed under the terms and conditions of the Creative Commons Attribution (CC BY) license (http:/ / creativecommons.org/licenses/by/4.0/). 